\title{
Comparison of various treatments for irritable bowel syndrome
}

\author{
J A RITCHIE, S C TRUELOVE
}

\section{Summary and conclusions}

A previous therapeutic trial of factorial design showed that a combination of a psychotropic drug, a smoothmuscle relaxant, and a bulk former (lorazepam, hyoscine hydrobromide, and ispaghula husk) relieved symptoms of the irritable bowel syndrome more effectively than the same agents given singly. Another trial of similar design was undertaken to compare each of these three agents with another having the equivalent clinical actionsnamely, Motival (fluphenazine/nortriptylene mixture), mebeverine, and bran. Ninety-six patients took part; all received three agents, one from each of the three pairs being compared, and no placebos were used. Fifty-six patients reported a sustained symptomatic improvement, which was a significantly higher incidence than in the previous trial, when placebos were used. Ispaghula was significantly more effective than bran. The combination of ispaghula, Motival, and mebeverine improved 11 out of 12 patients - significantly more than bran, Motival, and hyoscine (five improved), or bran, lorazepam, and mebeverine (four improved). Mebeverine was significantly more effective when combined with Motival (18 out of 24 improved) than with lorazepam (10 improved).

These results confirm the value of a combined therapeutic approach to the relief of the irritable bowel syndrome and suggest the possibility of synergism between agents.

\section{Introduction}

A previous double-blind controlled therapeutic trial of factorial design showed that a tranquilliser, a smooth-muscle relaxant, and a bulking agent (lorazepam, hyoscine butylbromide, and ispaghula respectively) were each more effective in producing a sustained symptomatic improvement in patients with the irritable bowel syndrome than the corresponding placebo preparation. ${ }^{1}$ Only in the case of ispaghula was the difference statistically significant. Combinations of two agents were marginally better than single agents, and the best results were obtained when all three were given together as a therapeutic package. Even so, only seven of the 12 patients who received this combination experienced a sustained improvement of their symptoms. As it was most unlikely that the three therapeutic agents used in the trial would necessarily represent the best of all those available, we undertook another study to compare the relative effectiveness of these three agents with that of three other agents that have similar clinical actions.

\section{Patients and methods}

The pair of psychotropic drugs we compared were lorazepam (Ativan) $1 \mathrm{mg}$ twice a day and a proprietary tablet (Motival) containing a tranquilliser (fluphenazine $0.5 \mathrm{mg}$ ) and an antidepressant (nortriptylene $10 \mathrm{mg}$ ), which was also given twice daily. The smoothmuscle relaxants were hyoscine butylbromide (Buscopan) $10 \mathrm{mg}$ four times a day, and mebeverine (Colofac) $135 \mathrm{mg}$ four times a day, while the bulking agents were ispaghula husk (Fybogel) $3.5 \mathrm{~g}$ twice a day and coarse natural bran, two tablespoons (about $20 \mathrm{~g}$ ) a day. Patients were warned that if the prescribed dose of either bulking agent seemed to increase discomfort initially, they should reduce their intake and work up to the full amount over one to two weeks.

Design of trial-Once again a factorial design was used. This provided for eight combinations of treatment which all included one of each pair of therapeutic agents. We were thus able to compare the clinical effectiveness of the two drugs in each pair of agents in terms of their actions in combination with the four possible permutations of the other two pairs of agents. The eight combinations of treatment used are shown in table I.

TABLE I-The eight combinations of treatment used. Each pair of agents is shown in same typeface

Ispaghula, lorazepam, hyoscine Bran, lorazepam, hyoscine Ispaghula, lorazepam, mebeverine, Bran, lorazepam, mebeverine Ispaghula, Motival, hyoscine, Bran, Motival, hyoscine Ispaghula, Motival, mebeverine, Bran, Motival, mebeverine

Patients were numbered consecutively on admission to the trial and were divided into blocks of eight patients. One of the eight possible combinations of treatment was issued to each member of a block by the hospital pharmacist, who worked from a randomised list. A total of 96 patients were brought into the trial to make up 12 randomised blocks.

Assessment of results-Because of the difficulty of assessing the efficacy of a therapeutic combination in patients with as wide a range of symptoms as those found in the irritable bowel syndrome, the same criteria of success or failure were used as in the previous trial. This had the additional advantage of keeping the two trials as comparable as possible. The treatment allocated to a patient was regarded as successful if the patient reported an overall improvement in symptoms after four weeks, and if the improvement was sustained throughout the rest of the three-month trial. Complete freedom from symptoms at both assessments occurred in only six cases, making this an unprofitable yardstick. Nine patients thought that their symptoms were exacerbated by the trial treatment, and their treatment was usually changed after the first four weeks, when they were counted as failures in the trial. Six of these nine were receiving Motival with hyoscine butylbromide, usually in combination with bran. In four cases patients either withdrew their consent, failed to take their allotted treatment, or moved away and were lost to follow-up. On each occasion, the trial number was reallocated to the next newcomer, who received the treatment combination due to that number under the original protocol. All the 96 patients who completed the trial had been fully investigated in a specialist gastroenterological outpatient clinic and no evidence had been elicited of any organic disease to account for their symptoms. Their ages ranged from 14 to 82 (mean 39 years), and $71(74 \%)$ were women.

\section{Results}

Of the 96 patients taking part in the trial $56(58 \%)$ reported an improvement in their symptoms which was maintained over the three months of the trial.

Comparison of single agents-Because each agent in each pair was 
combined with the same drugs as the other agent in the pair (table I) the efficacy of single agents of the same therapeutic class could be compared. Table II shows the different proportions of patients who reported improvement in symptoms after receiving one or other of the two alternative bulking agents, one of the two tranquillisers, and one of the two smooth-muscle relaxants. Ispaghula husk produced improvement in more patients than bran and Motival proved better than lorazepam, though only the difference between the two bulk formers was significant.

TABLE II-Comparison of therapeutic efficacy of two kinds of bulk former, two psychotropic drugs, and two smooth-muscle drugs. Each drug was taken by 48 patients

\begin{tabular}{lcccccc}
\hline \multicolumn{2}{r}{ Ispaghula } & Bran & Lorazepam & Motival & Hyoscine & Mebeverine \\
\hline No improved & $33^{*}$ & $23^{*}$ & 25 & 31 & 28 & 28 \\
\hline
\end{tabular}

*Significance of difference between ispaghula and bran: $\chi^{2}=4 \cdot 2 ; n=1 ; p<0.05$.

Comparison of pairs of drugs-Although there was no significant difference over the whole trial in success rates between lorazepam and Motival or between mebeverine and hyoscine butylbromide, the different ways in which they were combined produced important differences in therapeutic effect. Table I shows that, for each block of eight patients, the bulk formers (ispaghula husk and bran) were equally distributed between the four different combinations of two drugs, Motival plus mebeverine, lorazepam plus hyoscine butylbromide, Motival plus hyoscine butylbromide, and lorazepam plus mebeverine. As a result, the efficacy of the four pairs of drugs could be compared. Table III shows that, among the 48 patients given

TABLE III-Comparison of therapeutic efficacy of different combinations of a psychotropic drug and a smooth muscle relaxant. Each combination was taken by 24 patients

\begin{tabular}{cccccc}
\hline & $\begin{array}{c}\text { Motival } \\
+ \\
\text { mebeverine }\end{array}$ & $\begin{array}{c}\text { Lorazepam } \\
\text { +hyoscine }\end{array}$ & $\begin{array}{c}\text { Motival } \\
\text { +hyoscine }\end{array}$ & $\begin{array}{c}\text { Lorazepam } \\
+ \\
\text { mebeverine }\end{array}$ \\
\hline No improved & $\cdots$ & $18^{*}$ & 15 & 13 & $10^{*}$ \\
\hline
\end{tabular}

*Significance of difference: $\chi^{2}=5.5 ; n=1 ; p<0.05$.

mebeverine, 18 of the 24 who also received Motival were improved by the treatment whereas only 10 of the 24 who also took lorazepam showed comparable improvement. This was a statistically significant difference $\left(\chi^{2}=5 \cdot 5 ; p<0.02\right)$. On the other hand, patients who were taking hyoscine butylbromide and a bulking agent fared marginally better when these were combined with lorazepam than when they were combined with Motival.

Comparison of combinations of three agents-Table IV shows how many of each group of 12 patients reported a sustained improvement. The most effective combination was that of ispaghula husk, Motival, and mebeverine. The two least effective combinations, both of which were significantly less effective than the best combination, were bran, Motival, and hyoscine butylbromide and bran, lorazepam, and mebeverine.

TABLE IV-Comparison of therapeutic efficacy of the eight combinations of a bulk-former, psychotropic drug, and smooth-muscle relaxant. Each combination was taken by 12 patients

\begin{tabular}{|c|c|c|c|c|c|c|}
\hline & & & & & & No improved \\
\hline $\begin{array}{l}\text { Ispaghula, Motival, mebeverine } \\
\text { Ispaghula, lorazepam, hyoscine } \\
\text { Ispaghula, Motival, hyoscine } \\
\text { Bran, Motival, mebeverine .. } \\
\text { Bran, lorazepam, hyoscine } \\
\text { Ispaghula, lorazepam, mebeverine } \\
\text { Bran, Motival, hyoscine* } \\
\text { Bran, lorazepam, mebeverine } \\
\text { e }^{* *}\end{array}$ & $\begin{array}{l}\because \\
\because \\
\because \\
\cdots \\
\cdots\end{array}$ & $\begin{array}{l}\ldots \\
\because \\
\because \\
\because \\
\cdots\end{array}$ & $\begin{array}{l}\because \\
\because \\
\because \\
\because \\
\because\end{array}$ & $\begin{array}{l}. \\
\because \\
\because \\
\cdots \\
\cdots\end{array}$ & $\begin{array}{l}\because \\
\because \\
\because \\
\therefore \\
\therefore\end{array}$ & $\begin{array}{r}11 \\
8 \\
8 \\
7 \\
7 \\
6 \\
5 \\
4\end{array}$ \\
\hline
\end{tabular}

*Significance of difference from the best combination: $\chi^{2}=4.7 ; p<0.05$.
$* * \chi^{2}=6.4 ; p<0.02$.

\section{Discussion}

In the previous trial we concluded that a therapeutic package combining a tranquilliser, a smooth-muscle relaxant, and a bland bulking agent was probably more effective in relieving the symptoms of the irritable bowel syndrome than piecemeal treatment with single therapeutic agents. This impression has now been confirmed. Of the 96 patients treated in the first trial only 36 reported a sustained improvement compared with 56 of the 96 in the present trial, who all received a combination of three agents. This is a highly significant improvement $\left(\chi^{2}=8.3\right.$; $\mathrm{p}<0.01)$. The comparability of the results of the two trials is indicated by the close similarity between the success scores for the combination of ispaghula husk, lorazepam, and hyoscine butylbromide in both: seven out of 12 patients were improved in the first trial and eight out of 12 in the second.

The superiority of the gel bulk-former over ordinary bran calls in question the therapeutic value of bran in irritable bowel syndrome during the symptomatic stage. Such doubts have already been expressed by Søltoft et al, ${ }^{2}$ although their trial lasted only six weeks and involved a daily intake of $30 \mathrm{~g}$ of bran. In another trial undertaken by Brodribb ${ }^{3}$ in patients with symptomatic diverticular disease, which may or may not be strictly comparable, $6 \mathrm{~g}$ of fibre was given daily over three months. Benefit was assessed monthly and over the first four weeks the placebo was just as effective as the bran. After that the benefit of the placebo diminished and that of the bran progressively increased. Manning et al ${ }^{4}$ who gave $20 \mathrm{~g}$ of wheat bran daily for six weeks to patients with irritable bowel syndrome, found that it was beneficial in relieving pain and in improving bowel function and also that it lessened the prevalence of mucorrhoea. Fielding and Melvin ${ }^{5}$ have approached the problem from the opposite end using both bran and a high-fibre diet in 25 patients with irritable bowel syndrome. They found that the 20 patients who actually increased their fibre intake over six months reported an improvement in symptoms. The five patients whose fibre intake did not increase, and who appeared to have started from lower dietary levels, failed to improve. A comparison of bran and ispaghula, and also of lactulose, by Eastwood $e t$ al $^{6}$ in patients with diverticular disease showed that ispaghula was the only agent to increase stool weight significantly. Rather surprisingly, ispaghula also increased intraluminal pressures and motor activity in the distal bowel even more than lactulose, while bran diminished them. All three agents were equally valuable in producing an improvement in symptoms but one is bound to wonder whether constipated patients with diverticular disease are necessarily entirely comparable with patients with irritable bowel syndrome in terms of their response to treatment.

It is possible that early in the course of treatment for irritable bowel syndrome, when spasm of empty or scybalous bowel is a major factor in pain-production, bran, with its relatively high dry volume and low water binding capacity, may cause more obstructive symptoms and discomfort than a colloidal preparation. This hypothesis is supported by the observation in our trial that, although the patients were warned initially against overenthusiastic ingestion of bulking agents, 20 of the 31 who were unimproved after four weeks had been taking bran. This was a significantly higher proportion than that of the early failures who were on ispaghula $\left(\chi^{2}=3.86 ; p=0.05\right)$. Unfortunately, as all these patients counted as failures and were taken out of the trial, many then had their treatment changed so that it is not possible to say what proportion might have improved if they had persisted with bran during the following two months.

Mebeverine on its own has been the subject of doubleblind therapeutic trials, ${ }^{7} 8$ both of which showed it to be better than placebo in treating irritable bowel syndrome. When the drug is given in combination with others, the combination chosen appears to be of crucial importance. In the present trial, mebeverine with bran and lorazepam appeared to be no more effective than lorazepam on its own in our previous trial. On the other hand, the combination of mebeverine with ispaghula husk and Motival appeared outstandingly successful. 
The similarity of the success rates of mebeverine and hyoscine butylbromide is of particular interest in view of the opinion that hyoscine butylbromide ought to be wholly ineffective. ${ }^{910}$ In combination with lorazepam and a bulking agent, hyoscine butylbromide improved 15 out of 24 patients and was almost as effective as the combination of mebeverine with Motival and a bulking agent.

The use of a subjective measure of assessment in irritable bowel syndrome, such as a patient's impression of an improvement in symptoms, has been criticised as inappropriate when psychotropic drugs are included in the treatment. It is argued that a patient with symptoms of irritable bowel syndrome whose anxiety or depression is relieved is likely to feel better whatever his other treatment may be. There does not, however, appear to be much positive evidence to support such a view. In our previous trial lorazepam, alone or in combination, was the least effective of the three agents tested. In the present trial both lorazepam with mebeverine and Motival with hyoscine butylbromide scored less than the $58 \%$ average success rate. In addition, as part of the present trial, patients completed a psychometric questionnaire, the results of which will be reported elsewhere. This included a Beck Inventory ${ }^{11}$ to assess depression and a Spielberger Anxiety Trait Inventory. ${ }^{12}$ When the mean scores for these two inventories were determined and the therapeutic success rates for patients scoring above and below the means were stratified and compared they showed no significant differences. In particular, lorazepam was no more effective in improving symptoms in patients who were excessively anxious and Motival was no more efficacious in the patients who were relatively more depressed. Motival has not previously been tested in irritable bowel syndrome, though Motipress tablets, which are equivalent to three tablets of Motival, have been given in combination with bran at a dosage of one tablet at night (M J Lancaster-Smith et al, findings to be published). This treatment had beneficial effects on specific symptoms such as pain and diarrhoea in patients with irritable bowel syndrome. The doses given in the present trial were even smaller, and possibly ineffectual in psychotherapeutic terms, so the effects of lorazepam and Motival in irritable bowel syndrome may be unrelated to their psychotropic potential. Their site of action may be on the peripheral autonomic nervous system rather than on the brain.

It is clearly of importance to know whether the therapeutic value of Motival in combination with ispaghula husk and mebeverine in irritable bowel syndrome is attributable to the fluphenazine component or to the nortiptylene, or whether it is only in combination that these two drugs exert their beneficial effect, and this is currently under investigation.

One of us (JAR) is supported by a project grant from the Medical Research Council.

\section{References}

${ }^{1}$ Ritchie JA, Truelove SC. Treatment of irritable bowel syndrome with lorazepam, hyoscine butylbromide and ispaghula husk. $\mathrm{Br} \mathrm{Med} \mathcal{F} 1979$; i:376-8.

2 Søltoft J, Gudman-Høyer E, Krag B, Kristensen E, Wulfe MR. A doubleblind trial of the effect of wheat bran on symptoms of the irritable bowel syndrome. Lancet $1976 ; \mathrm{i}: 270-2$.

3 Brodribb AJM. Treatment of symptomatic diverticular disease with a high fibre diet. Lancet $1977 ; \mathrm{i}: 664-6$.

${ }^{4}$ Manning AP, Heaton KW, Harvey RF, Uglow P. Wheat fibre and the irritable bowel syndrome. Lancet 1977;ii:417-8.

${ }^{5}$ Fielding JF, Melvin K. Dietary fibre and the irritable bowel syndrome. F Hum Nutr 1979 ;33:243-7.

6 Eastwood MA, Smith AN, Brydon WG, Pritchard J. Comparison of bran, ispaghula and lactulose on colon function in diverticular disease. Gut 1978;19:1144-7.

7 Connell AM. Physiological and clinical assessment of the musculotropic agent mebeverine on the human colon. Br Med f 1965 ;ii:848-51.

8 Tasman-Jones C. Mebeverine in patients with the irritable colon syndrome; a double-blind study. $N Z \mathcal{F}$ Med 1973;77:232-5.

9 Herxheimer A, Haefeli L. Human pharmacology of hyoscine butylbromide. Lancet 1966 ;ii:418-21.

10 Herxheimer A, Misiewicz JJ. Oral hyoscine butylbromide for irritable bowel syndrome? $\mathrm{Br} M e d \mathcal{F} 1979 ; \mathrm{i}: 752$.

11 Beck AT. Depression. New York: Hoeber Medical Division, Harper and Rowe, 1967

12 Spielberger CD, Gorsucn RL, Lushene RE. The state-trait anxiety inventory; preliminary test manual for form $X$. Tallahassee, Florida: Florida State University, 1968.

(Accepted 7 October 1980)

\section{SHORT REPORTS}

\section{Intrinsic hazard of breech presentation}

Because perinatal mortality is higher with vaginal breech delivery ${ }^{1}$ elective caesarean section has been advocated for both term ${ }^{2}$ and preterm $^{3}$ deliveries. Nevertheless, the widespread practice of caesarean section for breech delivery at term has recently been questioned. ${ }^{4}$ The dangers of caesarean section are mostly to the mother, but it may sometimes be dangerous for the fetus 5 - particularly a preterm fetus when labour is far advanced. To assess how much neonatal depression after caesarean section is associated with breech presentation, we retrospectively studied the outcome of elective caesarean section at term when the fetus presented by the breech compared with the outcome when the presentation was cephalic.

\section{Patients, methods, and results}

Data were extracted from the Cardiff Birth Survey from 1970 to 1977, where records of 42357 singleton pregnancies are stored on magnetic tape. Only pregnancies resulting in a normal mature fetus of over $2.5 \mathrm{~kg}$ were considered and antepartum complications such as eclampsia or severe preeclampsia, antepartum haemorrhage, haemolytic disease, or heavy smoking and intercurrent medical disorders such as diabetes mellitus, epilepsy, essential hypertension, or chronic renal disease disqualified a patient from further study. All deliveries were by lower segment caesarean section under general anaesthesia. Results were compared by Student's $t$ test or the $\chi^{2}$ test.
A total of 110 breech and 436 cephalic presentations were suitable for study. There were no differences between the mothers in terms of age, weight, or social class distribution, but there were more multigravidae of shorter stature in the cephalic group.

There was no difference between the groups in terms of birth weight or placental weight, but a breech-presenting fetus was more likely to have had a low one-minute Apgar score and to have needed intubation than a cephalicpresenting fetus (table).

Details of 110 cases of breech and 436 of cephalic fetal presentation delivered at term by caesarean section

\begin{tabular}{|c|c|c|c|c|}
\hline & $\begin{array}{c}\text { Breech } \\
(n=110)\end{array}$ & $\begin{array}{l}\text { Cephalic } \\
(n=436)\end{array}$ & $t$ or $\chi^{2}$ & Significance \\
\hline $\begin{array}{l}\text { Mean }(\mathrm{SD}) \text { maternal } \\
\text { height }(\mathrm{cm}) \\
\text { Primipara }\end{array}$ & $\begin{array}{c}159 \cdot 3 \pm 66 \cdot 8 \\
48 \%\end{array}$ & $\begin{array}{l}157 \cdot 3 \pm 67 \cdot 3 \\
17 \%\end{array}$ & $\begin{array}{l}t=+2 \cdot 76 \\
\chi^{2}=45 \cdot 26\end{array}$ & $\begin{array}{l}\mathrm{p}<0.01 \\
\mathrm{p}<0.001\end{array}$ \\
\hline $\begin{array}{l}\text { Apgar score: } \\
<3 \\
4-6 \\
7-10 \\
\text { Required intubation }\end{array}$ & $\begin{array}{l}8.2 \% \\
26 \cdot 4 \% \\
64.5 \% \\
25 \%\end{array}$ & $\left.\begin{array}{r}4.6 \% \\
16 \cdot 1 \% \\
79 \cdot 0 \% \\
14 \%\end{array}\right\}$ & $\begin{array}{l}x^{2}=9.69 \\
x^{2}=7.46\end{array}$ & $\begin{array}{l}\mathrm{p}<0.01 \\
\mathrm{p}<0.01\end{array}$ \\
\hline
\end{tabular}

\section{Comment}

The difference in the proportions of primigravidae and mothers of short stature in the two groups reflects the practice of performing an elective caesarean section for cephalic presentations when there have been mechanical problems in a previous labour. The neonatal 